\title{
Case Report: Multidisciplinary Rehabilitation of a Patient With Neuromyelitis Optica
}

\author{
Mohammad Mohebbirad $^{1}$, Saeed Sheykh Chalandari² ${ }^{\text {DO }}$, Ghodsiyeh Joveini ${ }^{1^{*}}$ (D) \\ 1. Department of Occupational Therapy, School of Rehabilitation Sciences, Iran University of Medical Sciences, Tehran, Iran. \\ 2. Department of Speech Therapy, University of Social Welfare and Rehabilitation, Tehran, Iran.
}

\section{@(1)(@)}

*This work has been published under CC BY-NC-SA 4.0 license.

Article info:

Received: 13 Jul 2020

Accepted: 29 Aug 2020

Available Online: 01 Dec 2020

Funding

This research did not receive any specific grant from funding agencies in the public, commercial, or not-for-profit sectors.

Conflict of interest

The authors have no conflict of interest to declare.

\section{ABSTRACT}

Background and Objectives: Neuro Myelitis Optica (NMO) is a rare progressive and disabling autoimmune disease. The disabling consequences of the disease affect many aspects of the patients and their family life. multidisciplinary rehabilitation can be very effective in promoting quality of life and slowing disease progression by working with different disciplines. The aim of this study is to report the effects of multidisciplinary rehabilitation on the performance and quality of life of a patient with $\mathrm{NMO}$ and her family.

Case Report: This study reports a six-month multidisciplinary rehabilitation program conducted for a woman with NMO and her caregiver. The rehabilitation team included the patient's caregiver, a neurologist, an occupational therapist, and a speech therapist. The approaches of stabilization and recovery, maintenance, modification, and prevention were used through 70 sessions of occupational therapy. Also, the occupational performance was assessed with the Canadian Occupational Performance Measure. Furthermore, the Persian version of SF36 was used to assess the quality of life. The speech therapy intervention was performed in 24 sessions and included breath strengthening exercises, sound therapy, and laryngeal muscle manipulation. After six months, the results showed a great improvement in the quality of life of the patient and her caregiver.

Conclusion: The use of team approaches in the face of progressive neurodegenerative diseases such as NMO has a significant impact on improving the quality of life of these patients and their families.

Keywords: Multidisciplinary rehabilitation, Neuro Myelitis Optica, Occupational therapy, Speech therapy

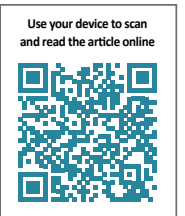

cite this artice as Mohebbirad M, Sheykh Chalandari S, Joveini Gh. Multidisciplinary Rehabilitation of a Patient With Neuromyelitis Optica. Function and Disability Journal. 2020; 3:69-76. http://dx.doi.org/10.32598/fdj.3.9

doi http://dx.doi.org/10.32598/fdj.3.9

* Corresponding Author:

Ghodsiyeh Joveini, PhD. Candidate

Address: Department of Occupational Therapy, School of Rehabilitation Sciences, Iran University of Medical Sciences, Tehran, Iran. Tel: +98 (21) 22228051

E-mail:joveiniot@yahoo.com
† What is "already known" in this topic:

Neuromyelitis Optica is a rare progressive neurodegenerative disease that affects many aspects of a patient and his or her family.

-What this article adds:

Using team approach and subject's cooperation influenced quality of life of the patient. 


\section{Introduction}

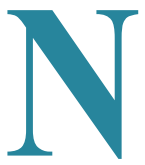

Neuro Myelitis Optica (NMO) is a rare autoimmune disease in which the myelin axons of the spinal and optic nerves are attacked by the immune system, resulting in widespread inflammation of the nerves [1]. The disease was previously known as a type of Multiple Sclerosis but was distinguished from the disease by the discovery of its unique antibody in 2004. The presence of aquaporin 4 anti-protein antibodies in these patients indicates that this protein, which is the main water channel in the membrane of nerve cells, is attacked, and especially the blood-brain barrier is disrupted $[2,3]$.

In these patients, a decrease or loss of vision and, depending on the degree of spinal nerve involvement, a range of symptoms of weakness, numbness, and paralysis of the limbs, muscle spasm, impaired bladder and bowel control, nausea, and hiccups are seen. Recurrence of seizures with a higher number and severity in the same period compared to patients with MS is seen in most of these patients [4]. However, although the main symptoms are related to ocular and spinal nerve involvement, cerebral atrophy and cognitive impairment, especially decreased sensory processing speed and long-term memory and attention deficits have also been reported in these patients [5-7].

NMO accounts for less than one percent of white populations and between 20 and 48 percent of demyelinating diseases in non-white populations, especially in Asia and Africa. Studies have shown that the prevalence and course of this disease in Iran are similar to white populations. In 2019, the prevalence of this disease in Iran was 1.31 per 100,000 people. The disease is more prevalent among women (more than $80 \%$ of cases) and the average age of onset of symptoms is 30 years [8].

The initial treatment after the first attack in these patients is a high dose of intravenous methylprednisolone and the next step is to change the blood plasma. After this stage, the main treatment is to prevent recurrence of the disease and recurrence of attacks with maintenance drugs such as Rituximab, Azathioprine, corticosteroids, etc. [9-12].

Because multiple factors are involved in progressive neurodegenerative diseases such as NMO, multidisciplinary rehabilitation can be very effective in promoting quality of life and slowing disease progression by working with different disciplines [13].

\section{Patient Description}

Patient (A) is a 42-year-old single woman living with her parents. she was a laboratory technician. Two years ago, after a few days of difficulty climbing stairs at work and feeling tired, he suffered his first attack and was hospitalized for two weeks. she began treatment with prednisolone and continued with oral corticosteroids. After stabilizing the discharge conditions and being severely restricted in daily activities, she was referred to occupational therapy by a neurologist. The evaluation and treatment process was performed according to the guidelines of the American Occupational Therapy Association (AOTA) for Neurodegenerative Diseases as follows [14]:

The occupational therapy evaluation process began with visiting the patient at home and preparing an occupational profile. The patient was confined to a wheelchair and the assessments showed spinal nerve involvement at levels C4 and C5. Based on the evaluation of sensation, range of motion, and muscle strength, no sensory and motor function was seen in the lower limbs and trunk Functional assessment of upper extremity ranges of motion indicated limitations in activities above shoulder level and muscle strength at levels 3 and 4 . On the other hand, there was severe spasticity in all limbs, which was mostly seen on the dominant side. Muscle weakness along with spasticity and fatigue had practically rendered the upper limb dysfunctional. The restrictions were so severe that they severely affected patient participation in all areas of occupation (basic and industrial activities of daily living, leisure, social participation, work, rest, and sleep). However, A had high self-confidence and strong morale. A's main caregiver was a 61-year-old housewife who was deeply disturbed by her daughter. The occupational therapist observed the mother's performance during transferring, feeding, tweeting and dressing of A to identify the facilitators and barrios of her participation in these activities. It was identified that inappropriate arrangement of home equipment, improper handling along with old age and the mother's inability were barriers in her participation. On the other hand, A's confident personality act as a facilitator.

The quality of life and occupational performance of $\mathrm{A}$, which according to the AOTA recommendation in patients with neurodegenerative diseases are among the main aberrations of occupational therapy programs, were evaluated. The occupational performance was assessed using the Canadian Occupational Performance Measure, which is one of the most widely used tools in this field in 


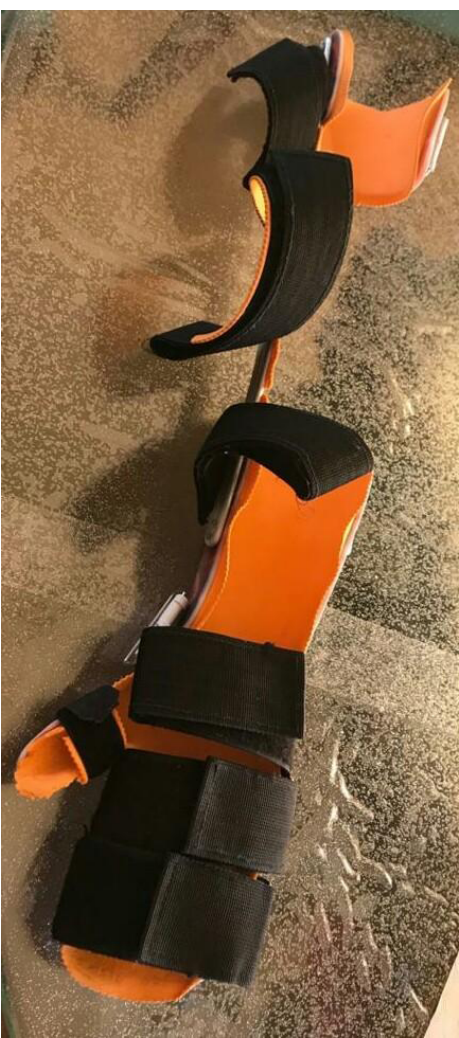

Figure 1. Wrist-Elbow Orthosis

occupational therapy [15]. The Persian version of 36SF was also used to assess the quality of life [16].

The treatment process was performed in three stages: planning, implementation, and review of interventions. The treatment schedule was determined as 3 sessions per week of home visits. The main goals of treatment focused on ADL and Leisure occupations. Interventions were performed based on 4 main approaches to occupational therapy in patients with neurodegenerative diseases as follows.

\section{Stabilization and recovery approach}

In order to manage high muscle tone, long stretching exercises with weight-bearing on the limbs were used. On the other hand, because the spasticity of the patient made it very difficult for the caregiver to handle the patient, the neurologist who supervised the patient was asked to provide appropriate medication if he deems it appropriate. Increasing the dose of the antispasmodic drug Tizanidine by the specialist helped to modulate the patient's tone. Also, due to the drowsiness side effects of this drug, the time of its use was adjusted so as not to interfere with treatment sessions.

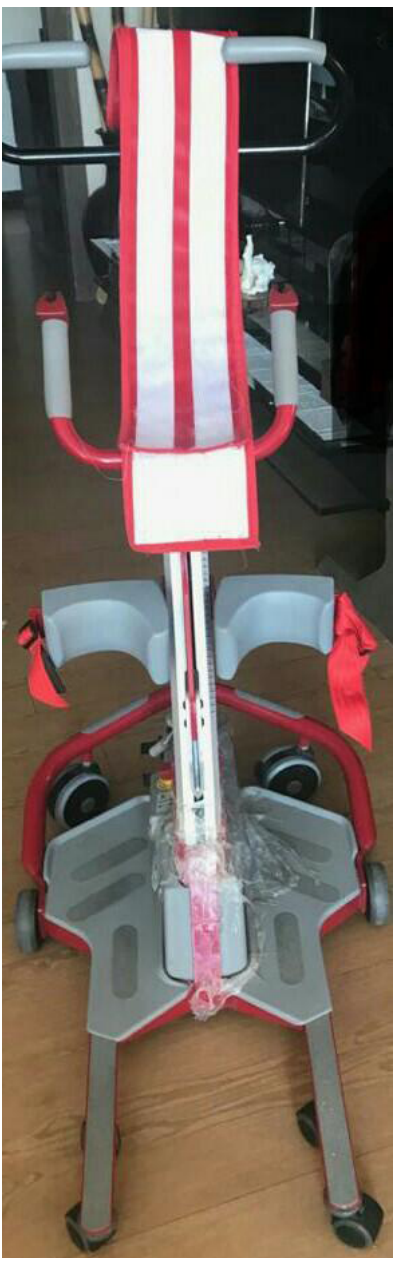

Figure 2. Lifter for the Indoor Moving of the Patient's

\section{Maintenance approach}

In order to maintain the range of motion of the joints and to prevent muscle shortening and proper posture of the patient on the bed and wheelchair, passive range of motion exercises for the joints were taught to the mother according to a regular daily schedule. A pair of wrist elbow orthosis was also prescribed for proper positioning of the upper limb (Figure 1) and a pair of Ankle Foot Orthosis for the lower limb.

\section{Modification approach}

In order to move inside the house, a lifter was purchased at the suggestion of the therapist (Figure 2). To fit the patient, two cotton pads were inserted in the lower part of the elevator and they were taught how to get on and off it. Changes were made to the arrangement of household items to make it easier for the patient to move around the house. The entrance of the bathroom was adjusted to fit the elevator and the equipment inside the bathroom was moved for proper rotation. In the bath, a bar was 


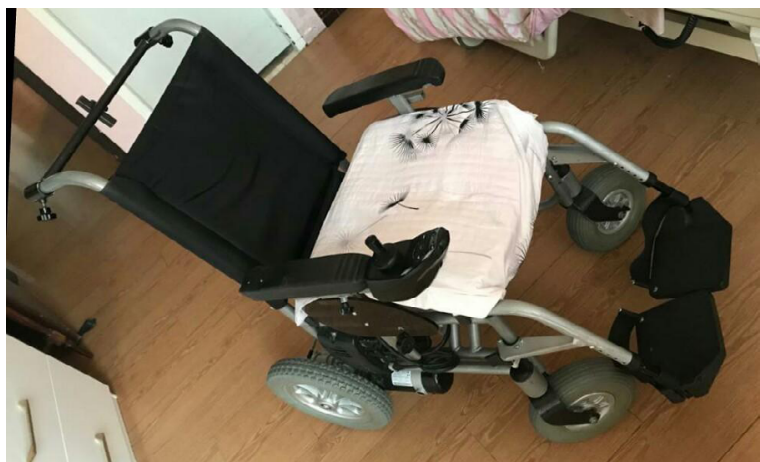

Figure 3. Electric wheelchair for indoor and outdoor moving

installed at the patient's sitting height. The use of matching glasses, spoons, and forks led to self-feeding independence. To facilitate putting the patient in the car, a lifter for the car, and an electric wheelchair (Figure 3) were purchased for transportation outside the house. Leisure activities inside and outside the home were planned and activities were determined in consultation with the patient and caregivers. Because he was interested in reading, prescribing a book stand helped him to do this activity more independently. On the other hand, it was planned to go to parties, parks, restaurants, and travel.

\section{Preventive approach}

In order to prevent bedsores, the caregiver was instructed in the regular examination and skincare methods. Cognitive-behavioral methods and expressive activities were used to control stress and prevent depression. To prevent pressure on the caregiver's body, the caregiver was instructed on the correct way of handling the patient to move, change the patient's clothes and bathe.

Due to the high level of anxiety of the main caregiver (mother), each session was allocated half an hour to psychological interventions. He was first referred to a neurologist for medication interventions to control anxiety. Gabapentin was prescribed for him. Daily breathing exercises, muscle relaxation and meditation were taught to the mother and each session was practiced. Expressive activities were used to express themselves and their thoughts about stressors. In order to create the mother's occupational balance recreational activities and getting help from other people in doing related tasks were also used.

After 70 sessions of occupational therapy in 6 months, there was a great increase in the quality of life of $A$ and her mother, based on SF36 results.

\section{Speech therapy interventions}

Speech therapy interventions in this patient include exercises to strengthen breathing, sound therapy, and laryngeal muscle manipulation.

In the field of strengthening breathing processes, exercises include improving the Maximum Phonation Time (MPT) [17] (MPT), improving the tail air capacity through a spirometer [18], regulating the function of inhaling and exhaling, eliminating shoulder breathing and improving abdominal breathing and approach. The treatment is the Buteyko Breathing Technique (BBT). BBT therapy is a technique based on improving the quality of life with three factors of nutrition, exercise, and creating general relaxation that includes maximum oxygen uptake and the ratio of oxygen to carbon dioxide [19]. In the field of sound therapy, exercises include relieving hoarseness, improving vocal hygiene, increasing sound accessibility by changing the position of the voice, and improving the vibration oscillation of the vocal cords. According to the Gantt chart of the treatment process, in the first 12 weeks of treatment, one treatment session was held each week focused on improving respiratory capacity.

The results showed an increase in MPT from 5 seconds to 21 seconds and an improvement in tail air capacity from about $500 \mathrm{ccs}$ to $1,200 \mathrm{ccs}$ through spirometer exercises. In the field of voice counseling, improving voice health is one of the main approaches to prevention and treatment. Voice health is a set of functions to maintain and improve the quality of a person's voice, which includes not using sound in a noisy environment, not consuming caffeinated substances, and casein The use of hot and cold fumigators and regular water consumption were considered [20]. Treatment was followed 6 weeks later with a dose of 2 sessions per week focusing on voice therapy exercises and the results show the overall improvement of hoarseness through the Voice Disability Index (VHI) questionnaire taken before and after the sessions. The results do not show a significant change in the volume of the sound. Laryngeal muscle manipulation approaches were performed to improve sound quality and relieve muscle spasms in 10 sessions of 10 minutes per session [21]. The results after the sessions showed that the spasms in the larynx and SCM muscles were relieved and the patient complained of pain in the neck muscles. 


\section{Discussion}

In progressive neurodegenerative diseases, the goal of drug therapy is to reduce the rate of degradation of disease progression. While the focus of rehabilitation interventions is to maintain patient function despite disease progression. These interventions are used throughout the disease from early to advanced stages. In the course of the disease, there are many problems such as spasticity, weakness, limited mobility, fatigue, pain, cognitive, mood and communication disorders, intestinal and bladder control disorders, swallowing and speech problems, limitation in daily life activities such as eating, dressing and Relocation, doing housework, and continuing to work and maintain income are created for the patient. To deal with a large set of evolving and changing disabilities, the teamwork of a set of experts is essential. The group of interdisciplinary specialists can include a neurologist, psychiatrist, and other medical specialties, a nurse, physiotherapist, occupational therapist, speech therapist, psychologist, social worker, patient, family, and caregivers. Group cooperation between members, in addition to the impact on neurological deficits, helps to reduce or prevent many disabilities and secondary problems by establishing appropriate communication and creating a sense of productivity increases the quality of life of the patient and his family [13]. This study is the first study in Iran in which a report is presented on the effect of teamwork between a neurologist, occupational therapist, speech therapist, patient, and their caregivers in improving the performance and quality of life of a patient with NMO and his caregiver. In Iran, the use of group approaches and collaboration between specialists is weak and little attention has been paid to the impact of this approach on neurological patients such as NMO. It should be noted that rehabilitation services and interventions are not separate or additional services and are not extraneous to medical and pharmaceutical services and should be provided together.

\section{Conclusion}

The use of team approaches in the face of progressive neurodegenerative diseases such as NMO has a significant impact on improving the quality of life of these patients and their families. In this regard, the presence and cooperation of the rehabilitation team along with medical professionals is very important.

\section{Ethical Considerations}

\section{Compliance with ethical guidelines}

All ethical principles are considered in this article. The participant is informed of the purpose of the research and its implementation stages; the subject were also assured about the confidentiality of the information and was free to leave the study whenever she wished, and if desired, the research results would be available to her.

\section{Funding}

This research did not receive any specific grant from funding agencies in the public, commercial, or not-forprofit sectors.

\section{Authors' contributions}

Conceptualization, supervision: Mohammad Mohebbirad, Saeed Sheykh chalandari; Methodology and writing original draft: Ghodsiyeh Joveini; review \& editing: All authors.

\section{Conflict of interest}

The authors have no conflict of interest to declare.

\section{References}

[1] Wingerchuk DM, Lennon VA, Lucchinetti CF, Pittock SJ, Weinshenker BG. The spectrum of neuromyelitis optica. Lancet Neurol. 2007; 6(9):805-15. [DOI:10.1016/S1474-4422(07)70216-8]

[2] Lennon VA, Wingerchuk DM, Kryzer TJ, Pittock SJ, Lucchinetti $\mathrm{CF}$, Fujihara K, et al. A serum autoantibody marker of neuromyelitis optica: Distinction from Multiple Sclerosis. Lancet (London, England). 2004; 364(9451):2106-12. [DOI:10.1016/S01406736(04)17551-X]

[3] Lennon VA, Kryzer TJ, Pittock SJ, Verkman AS, Hinson SR. IgG marker of optic-spinal multiple sclerosis binds to the aquaporin-4 water channel. J Exp Med. 2005; 202(4):473-7. [DOI:10.1084/ jem.20050304] [PMID] [PMCID]

[4] Duan Y, Liu Y, Liang P, Jia X, Yu C, Qin W, et al. Comparison of grey matter atrophy between patients with neuromyelitis optica and multiple sclerosis: A voxel-based morphometry study. Eur J Radiol 2012; 81(2):e110-4. [DOI:10.1016/j.ejrad.2011.01.065] [PMID]

[5] Calabrese M, Oh MS, Favaretto A, Rinaldi F, Poretto V, Alessio $\mathrm{S}$, et al. No MRI evidence of cortical lesions in neuromyelitis optica. Neurology. 2012; 79(16):1671-6. [DOI:10.1212 WNL.0b013e31826e9a96] [PMID] 
[6] Blanc F, Noblet V, Jung B, Rousseau F, Renard F, Bourre B, et al. White matter atrophy and cognitive dysfunctions in neuromyelitis optica. PLoS One. 2012;7(4):e33878. [DOI:10.1371/journal. pone.0033878] [PMID] [PMCID]

[7] Blanc F, Zephir H, Lebrun C, Labauge P, Castelnovo G, Fleury $\mathrm{M}$, et al. Cognitive functions in neuromyelitis optica. Arch Neurol. 2008; 65(1):84-88. [DOI:10.1001/archneurol.2007.16]

[8] Rezaeimanesh N, Sahraian MA, Moghadasi AN. Eskandarieh SH. Epidemiology of neuromyelitis optica spectrum disorder in Tehran, Iran: the prevalence, baseline characteristics, and clinical aspects. Neurol Sci. 2020; 41(9):2647-8. https://doi.org/10.1007/s10072020-04393-7

[9] Trebst C, Jarius S, Berthele A, Paul F, Schippling S, Wildemann B, Borisow N, et al., \& Neuromyelitis Optica Study Group. Update on the diagnosis and treatment of neuromyelitis optica: recommendations of the Neuromyelitis Optica Study Group (NEMOS). J Neurol. 2014; 261(1):1-16. [DOI:10.1007/s00415-013-7169-7] [PMID] [PMCID]

[10] Merle H, Olindo S, Jeannin S, Valentino R, Mehdaoui H, Cabot $\mathrm{F}$, et al. Treatment of optic neuritis by plasma exchange (add-on) in neuromyelitis optica. Arch Ophthalmol. 2012; 130(7):858-862 [DOI:10.1001/archophthalmol.2012.1126] [PMID]

[11] Costanzi C, Matiello M, Lucchinetti CF, Weinshenker BG, Pittock SJ, Mandrekar J, et al. Azathioprine: Tolerability, efficacy, and predictors of benefit in neuromyelitis optica. Neurol. 2011; 77(7):659-666. [DOI:10.1212/WNL.0b013e31822a2780] [PMID]

[12] Kim SH, Jeong IH, Hyun JW, Joung A, Jo HJ, Hwang SH, et al. Treatment outcomes with rituximab in 100 patients with neuromyelitis optica: influence of FCGR3A polymorphisms on the therapeutic response to rituximab. JAMA Neurol. 2015; 72(9):989-95. [DOI:10.1001/jamaneurol.2015.1276] [PMID]

[13] Dehghan L, Dalvand H, Pourshahbaz A. [Translation of Canadian occupational performance measure and testing Persian version validity and reliability among Iranian mothers of children with cerebral palsy (Persian)]. J Mod Rehabil. 2015; 9(4):25-31. http://mrj.tums. ac.ir/article-1-5349-fa.htm

[14] American Occupational Therapy Association. Occupational Therapy Practice Framework: Domain And Process, $3^{\text {rd }}$ Edition. Am J Occup Ther. 2014; 68(Supplement 1):S1-S48. [DOI:10.5014/ ajot.2014.682006]

[15] Lundy DS, Casiano RR, Xue JWJTL. Can maximum phonation time predict voice outcome after thyroplasty type I? Laryngoscope. 2004; 114(8):1447-54. [DOI:10.1097/00005537-20040800000025] [PMID]

[16] So MW, Heo HM, San Koo B, Kim YG, Lee CK, Yoo B. Efficacy of incentive spirometer exercise on pulmonary functions of patients with ankylosing spondylitis stabilized by tumor necrosis factor inhibitor therapy. J Rheumatol. 2012; 39(9):1854-8. [DOI:10.3899/ jrheum.120137] [PMID]

[17] Bruton A, Lewith GT. The Buteyko breathing technique for asthma: A review. Complement Ther Med. 2005; 13(1):41-6. [DOI:10.1016/j.ctim.2005.01.003] [PMID]

[18] Broaddus-Lawrence PL, Treole K, McCabe RB, Allen RL, Toppin L. The effects of preventive vocal hygiene education on the vocal hygiene habits and perceptual vocal characteristics of training singers. J Voice. 2000; 14(1):58-71. [DOI:10.1016/S08921997(00)80095-8]
[19] Van Lierde KM, De Ley S, Clement G, De Bodt M, Van Cauwenberge P. Outcome of laryngeal manual therapy in four Dutch adults with persistent moderate-to-severe vocal hyperfunction: A pilot study. J Voice. 2004; 18(4):467-74. [DOI:10.1016/j. jvoice.2004.02.003] [PMID]

[20] Burks JS, Bigley GK, Hill HH. Rehabilitation challenges in Multiple Sclerosis. Ann Indian Acad Neurol. 2009; 12(4):296-306. [DOI:10.4103/0972-2327.58273] [PMID] [PMCID]

[21] Javanmard SH, Rabbani H. (2011). Interdisciplinary researches in Iran. J Med Sign Sen. 1(2):89-90. [DOI:10.4103/2228-7477.95291] [PMID] [PMCID] 


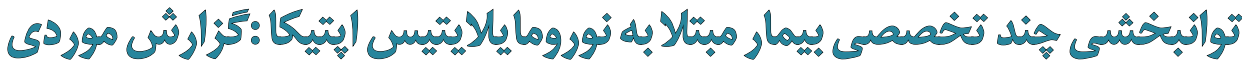

\author{
محمد محبىراد'، سعيد شيخ جلندرى '0.، "قدسيه جوينى' \\ ا. ا.كروه كاردرمانى، دانشكده علوم توانبخشى، دانشكاه علوم يزّشكى ايران، تهران، ايران.



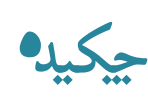

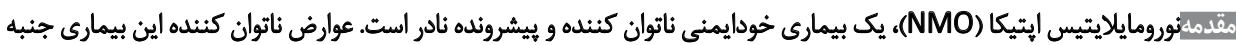

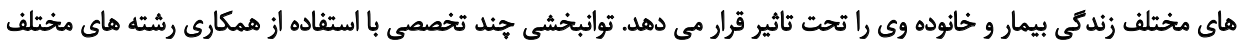

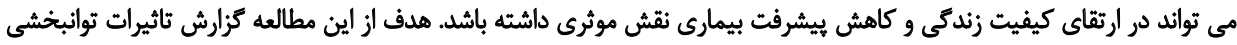

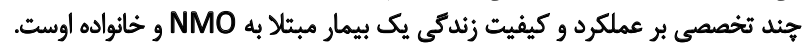

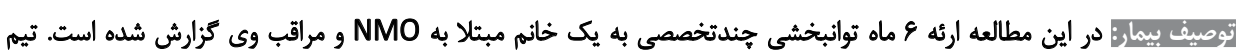

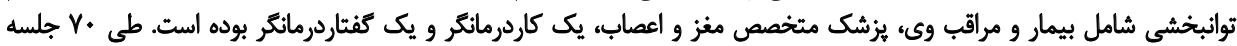

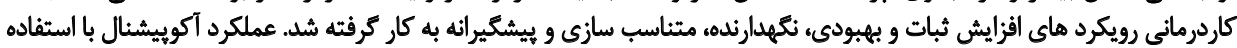



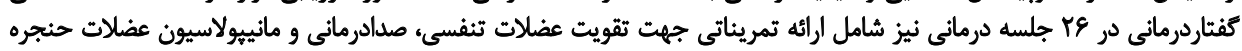

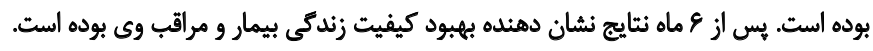

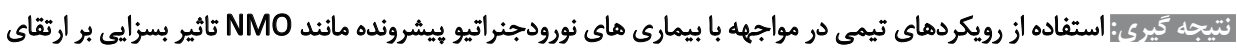

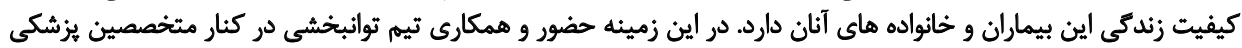
بسيار حائز اهميت استى اين بيمان

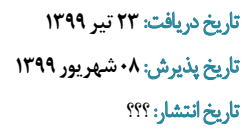

كليدوازوها:

توانبخشى تخصى

نورومايلايتيس إيتيكا، كاردرمانى، كفتاردرمانيى إنيكي

doi $h$ http://dx.doi.org/10.32598/fdj.3.9 
This Page Intentionally Left Blank 